$$
\lim _{x \rightarrow 0} \frac{\ln (1+x)}{x}=\lim _{x \rightarrow 0}\left[\ln (1+x)^{\frac{1}{x}}\right]=\ln \left[\lim _{x \rightarrow 0}(1+x)^{\frac{1}{x}}\right]=\ln e=1 .
$$

Тогда система дифференциальных уравнений (13) будет определять динамику фильтрационных процессов в перфорационных каналах ствола горизонтальных скважин сложной геометрии, а шкала сравнения бесконечно малых величин, будет служить критерием физического смысла при интерпретации результатов геофизических исследований интервала продуктивного пласта методами дифференциальной телеметрии.

\title{
Заключительные замечания
}

Изложенная выше методика по оценке динамики фильтрационных процессов в перфорационных каналах интервала продуктивного пласта ствола горизонтальных скважин, в основном предназначена для дифференциальных измерительных преобразователей скважинных телеметрических систем, построенных на основе современных волоконно-оптических датчиков.

В основу датчиков и измерительных преобразователей стандартных телеметрических систем различных геофизических методов заложены принципы преобразования неэлектрических величин в электрические, которые основаны на механических, физических и химических способах преобразования. Поэтому, для стандартных телеметрических систем, изложенная методика может быть и не приемлема в полной мере по причине недостаточной чувствительности и высокой погрешности морально устаревших датчиков, т. е. не выполняется условие:

$$
\varepsilon \ll\left\{\begin{array}{l}
\sigma_{\rho} ; \\
p ; \\
v ;
\end{array}\right.
$$

Это ограничение в применении изложенной методики не является недостатком. Оно рассматривается как переход от устаревших технологий исследования скважин машинно-энергетических, информационно-компьютерных к новой и молодой области техники - молекулярно-квантовой, которая определяется современным термином «нано технологии».

$$
* * *
$$

1. Маскет М. Течение однородных жидкостей в пористой среде. - Москва - Ижевск: Институт компьютерных исследований, 2004. - 640 с.

2. Ландау Л. Д., Лифшиц Е. М. Теоретическая физика. В 10-ти т. Т. VI. Гидродинамика. - 4-е изд. стер. - М.: Издательство «Наука». Главная редакция физико-математической литературы, 1988. $736 \mathrm{c}$.

3. Кошляков Н. С., Глинер Э. Б., Смирнов М. М. Основные дифференциальные уравнения математической физики. - М.: Государственное издательство физико-математической литературы, 1962. - $768 \mathrm{c}$.

4. Тихонов А. Н., Самарский А. А. Уравнения математической физики. - 7-е изд. - М.: Издательство МГУ; Издательство «Наука», 2004. - 798 с.

5. Пискунов Н. С. Дифференциальное и интегральное исчисления. В 2-х т. Т. 1. - М.: Издательство «Интеграл-Пресс», 2005. - 416 с.

Кутырин Б.А., Деянов Д.А.

Оценка распределения выбросов дисперсных частиц транспортными потоками по территории города с использованием ГИС-технологии

Московский автомобильно-дорожный государственный технический университет (МАДИ)

(Россия, Москва)

doi: $10.18411 / 1 j-06-2020-99$

idsp: ljournal-06-2020-99

\section{Аннотация}

В данной статье приведен пример оценки и сравнения данных использованием методики кластеризации данных при разработке и оценке экологической 
эффективности территориального планирования в городе Москве. Объектом исследования является улично-дорожная сеть города и оценка распределения выбросов загрязняющих веществ от нее на территории города при помощи ГИС технологий.

Ключевые слова: территориальное планирование, загрязнение воздуха, геоинформационные системы, кластерный анализ, сравнение показателей,

\section{Abstract}

This article provides an example of evaluating and comparing data using data clustering techniques in the development and evaluation of the effectiveness of spatial planning in the city of Moscow. Network research in this area is an estimate of the number of objects located throughout the city using GIS technology.

Keywords: air pollution, spatial planning, geographic information systems, comparison of indicators, pollution assessment. cluster analysis.

Введение. Территориальное планирование - планирование развития территорий, в том числе для установления функциональных зон, зон планируемого размещения объектов капитального строительства для государственных и муниципальных нужд, зон с особыми условиями использования территорий. Сущность территориального планирования раскрывается в определении в документах территориального планирования функционального назначения территорий, исходя из совокупности социальных, экономических, экологических и иных факторов в целях обеспечения учета интересов граждан и их объединений [1].

Территориальная привязка к местности и времени выбросов транспортных потоков позволяет получить более наглядную и достоверную информацию об экологическом благополучии на всей территории крупного города, где основным источником загрязнения является автомобильный транспорт.

В работе рассмотрена технология оценки экологической эффективности территории крупного города по интенсивности выбросов загрязняющих веществ в атмосферу от транспортных потоков на улично-дорожной сети с помощью геоинформационных систем (ГИС).

ГИС все чаще начинают применяться для решения различных задач моделирования процессов и ситуаций. Интеллектуальные ГИС осуществляют комплексный анализ и интерпретацию разнотипных данных и, как правило, включают в себя средства поддержки принятия решений. [2].

Существующие методы территориальной привязки с помощью ГИС.

Основные способы:

1) модели пространственных данных:

a) растровые модели данных;

b) векторные модели данных:

(1) векторные нетопологические;

(2) векторные топологические модели.

2) ГРИД представление;

3) TIN представление;

4) модель «Сущность-связь» [3].

Оценка распределения выбросов дисперсных частиц транспортными потоками по территории города Москвы в 2011 и 2018 годах с помощью ГИС.

Расчетные оценки выбросов дисперсных частиц транспортными потоками на УДС города выполнены с использованием программного комплекса COPERT V [4]. Исходными данными для проведения расчетов и их визуализации были:

— конфигурация и протяженность улично-дорожной сети города (важным условием оценки улично-дорожной сети является детальное изучение карты города. Стоит отметить, что данные 2011 и 2018 года сильно 
разняться, по причине добавления или удаления дорог, а также изменения градостроительной политики);

— плотность улично-дорожной сети города;

— категория улиц города;

- число полос движения (для наиболее точного определения данного показателя были рассмотрены предоставленные в открытом доступе спутниковые снимки. Поскольку речь идет о линейных объектах для использования в модели были выбраны реальные значения показателя на определенном отрезке без усреднения по полосам);

- интенсивность, средняя скорость движения, состав транспортного потока;

— численность автомобильного парка (для расчета данного показателя были использованы данные ЦОДД и ГИБДД);

- структура автомобильного парка по типу АТС, экологическому классу и виду используемого топлива.

Принципиально важным моментом данной работы является задача привязки полученных значений валовых выбросов загрязняющих веществ, генерируемых транспортным потоком в секторах улично-дорожной сети ко всей территории города Москвы в пределах МКАД.

Для решения данной задачи была произведена разбивка территории города с использованием геоинформационных технологий на участки размером $580 \times 580$ м (всего 2849 участков). Внутри каждого из участков территории была определена протяженность УДС, с привязкой к полосе движения. Таким образом удалось добиться высокой достоверности данных, используемых для расчетов в ГИС. Привязка к полосе движения так же дала возможность для каждого участка УДС оценивать дорогу в разных направлениях по-разному с учетом их действительной загрузки и средней скорости движения [5].

С учетом этих данных, а также удельных значений (на 1 км 1-й полосы движения) выбросов дисперсных частиц, была осуществлена привязка валовых выбросов дисперсных частиц от транспортных потоков в 2011 и 2018 годах на всей территории города. Разница между выбросами была посчитана в автоматическом режиме с помощью ГИС - технологии. Результат изменения выбросов твердых дисперсных частиц продемонстрирован на рисунке 1.1.

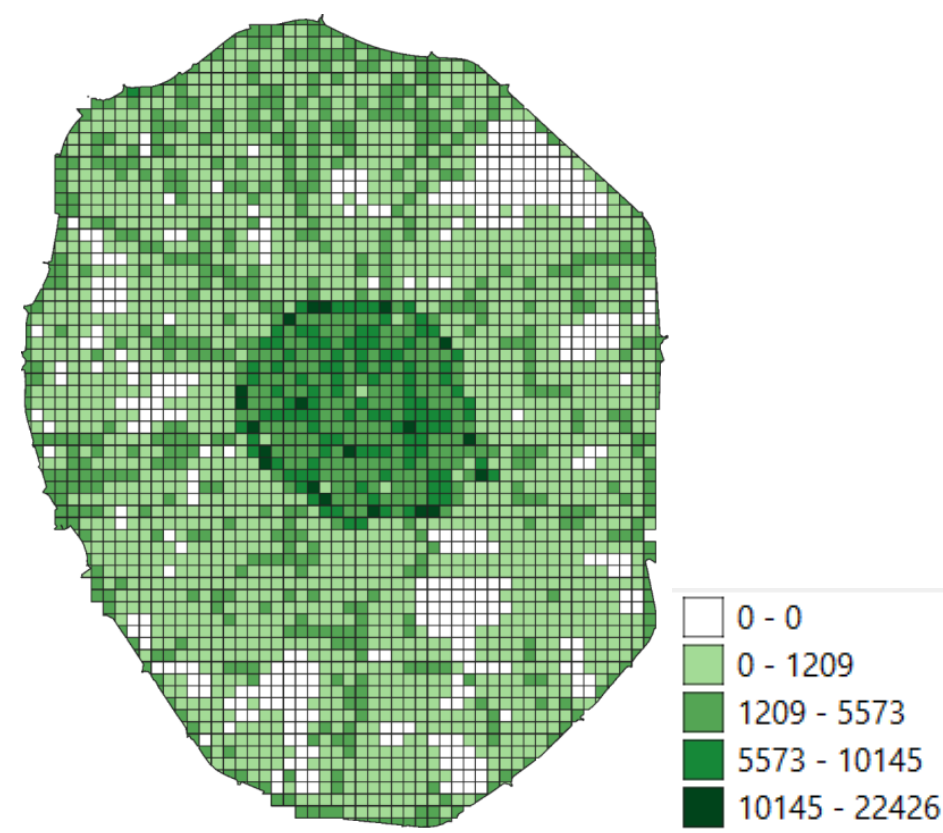

Рисунок 1 - Сокращение выбросов дисперсных частиц на территории города от автомобильного транспорта в 2018 году по сравнению с 2011 годом, кг/год 
Разбиение полученных результатов оценки на кластеры, как видно из рис. 1, способствовало улучшению наглядности при их визуализации.

Следует отметить, что геоинформационные системы позволяют проводить кластерный анализ в автоматическом режиме. Существует пять основных видов деления результатов на кластеры:

— равные интервалы;

- естественные интервалы;

- стандартное отклонение;

- наглядные интервалы;

- Equal Count или принцип, именуемый «Равное количество».

Для кластеризации выбросов твердых дисперсных частиц использован вид деления территории на кластеры - Equal Count. Результаты кластерного анализа в ГИСтехнологиях могут быть представлены как в графическом (рис. 1), так и числовом виде (таблица 1).

Таблица 1.

Результаты кластерного анализа территории по выбросам дисперсных частии от транспортных потоков в числовом виде

\begin{tabular}{|c|c|c|c|c|c|c|c|}
\hline \multirow{2}{*}{$\begin{array}{c}\text { № } \\
\text { пп }\end{array}$} & $\begin{array}{c}\text { Диапазоны } \\
\text { изменения } \\
\text { выбросов твердых } \\
\text { частиц, кг/год }\end{array}$ & \multicolumn{2}{|c|}{ Кол- во, участков территории 580 х } & \multicolumn{3}{|c|}{ Площадь территории, км2 } \\
\cline { 5 - 9 } & 2011 & 2018 & Разница & 2011 & 2018 & Разница \\
\hline 1 & $0-602$ & 407 & 430 & +23 & 136,9 & 144,6 & 7,7 \\
\hline 2 & $602-3095$ & 410 & 606 & +196 & 137,9 & 203,8 & 65,9 \\
\hline 3 & $3095-4697$ & 404 & 523 & +119 & 135,9 & 175,9 & 40 \\
\hline 4 & $4697-6173$ & 412 & 471 & +59 & 138,6 & 158,4 & 19,8 \\
\hline 5 & $6173-7796$ & 401 & 353 & -48 & 134,9 & 118,7 & $-16,2$ \\
\hline 6 & $7796-10382$ & 407 & 254 & -153 & 136,9 & 85,4 & $-51,5$ \\
\hline 7 & $10382-38134$ & 408 & 206 & -202 & 137,2 & 69,3 & $-67,9$ \\
\hline
\end{tabular}

\section{Заключение.}

Использование ГИ-технологий наглядно отображают тенденцию снижения выбросов дисперсных частиц в городе Москве, позволяют визуально и численно определить наиболее загрязненные участки территории. Установлено, что в 2018 году по сравнению с 2011 годом, площадь территории, с высоким и очень высоким уровнем выбросов дисперсных частиц сократилась почти в 2 раза (с 274,1 км2 до 154,7 км2). Одновременно возросла площадь территории с низким уровнем выбросов дисперсных частиц.

\section{$* * *$}

1. Леонов С.О. Роль территориального планирования в управлении земельными ресурсами субъекта РФ (на примере Ленинградской области): Магистерская диссертация. - М., 2016. - 124 с.

2. Шульдешов Ю.Л., Ларионов Д.Ю. Методы обработки пространственных данных с использованием экспертной системы // Труды СПИИРАН. 2011. Вып. 2. С. 219-233

3. Ананьев Ю.С. Геоинформационные системы: учеб. пособие. Томск: Изд-во ТПУ, 2003. 70 с.

4. The industry standard emissions calculator // COPERT | EMISIA SA URL: https://www.emisia.com/utilities/copert/ (дата обращения: 02.05.2020).

5. Ю.В. Трофименко, М.Р. Якимов. Транспортное планирование: формирование эффективных транспортных систем крупных городов: монография. М.: Логос, 2013. 464 с. 